\section{El retiro de bienes}

Chávez Ocharán, Samy ${ }^{1}$

Universidad Peruana Unión (UPeU), Perú

Recibido 28 de julio de 2014 - Aceptado el 28 de octubre de 2014

\section{Resumen}

El Impuesto General a las Ventas (IGV) - impuesto que grava el consumo de bienes y servicios- ha estimulado, desde su legislación, diferentes interrogantes en los expertos en materia tributaria. Sin embargo, no es el impuesto en sí el principal motivo de investigación So las extensiones que este impuesto conleva, de bienes. La ley del IGV considera la pecuniaria- se ven afectas a este gravamen; este fundamento es el móvil que lleva a diferentes entendidos a cuestionar su afectación, as como su aplicación.

Palabras Clave: Retiro de bienes, transferencias gratuitas, autoconsumo.

\section{Abstract}

The General Sells Tax (IGV) - a tax which is placed to the consumption of goods and services - has estimulated, since its legislation, several queries in the taxes' experts. However, it is not the tax itself the main reason of research but the extensions that comes with it, being one of them the withdrowal of goods. The legislation of the IGV considers the free transfers and the self-supplies as withdrowal of goods, which -even being free transactions of pecuniary consideration- are levied with this tax; this basis is the motive which, many experts take into account to question its levy as well as its implementation.

Keywords: Withdrowal of goods, free transfers, self-supply

\section{Introducción}

La problemática que abre la puerta a realizar el presente rabajo de investigación es la falta de conocimiento acerca de la extensión normativa de la ley del Impuesto General a las Ventas, el retiro de bienes.

Una de las razones principales de ocurrencia del problema en estudio es la informalidad, según Loayza (2007) en el Perú, el 60\% de la producción se realiza for ent ex $40 \%$ de la fuerza laboral esta a for está

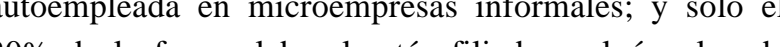
$20 \%$ de la fuerza laboral está afiliado a algún plan de pensiones formal, incluso si se incluye a aquellos trabajadores que laboran para empresas grandes. En el mismo estudio señala que el Perú es el país más informal en los cuatro indicadores de informalidad referida en contraste a Colombia y México (países ambos con similares niveles de ingresos), a Chile (el país con la más alta tasa de crecimiento sostenido de América Latina).

Por otro lado, nuestro país no posee una alta cultura tributaria, dado que la mayoría de empresas buscan las maneras de evitar todos los impuestos que se les sea tributaria global de $16.9 \%$ del PBI, el segundo pico más alto del periodo analizado.

A simismo, Ledesma (2011) menciona que del total de ingresos por tributos en el año 2010, los impuestos al consumo (IGV) aportaron con el $62 \%$, también menciona que la evasión tributaria del impuesto general a las ventas equivale a $3.6 \%$ del PBI, teniendo en cuenta que el retiro de bienes es preponderante en este porcentaje. El objetivo del presente artículo es definir el retiro de bienes dentro del marco teórico contemporáneo, comando en cuenta su origen, implicancias y subdivisiones.

\section{mpuesto general a las ventas}

\section{Definición}

El impuesto general a las ventas (IGV) se conceptualiza dentro de las manifestaciones exteriores del consumo y tiene la característica preponderante de ser un impuesto netamente plurifásico no acumulativo.

Según B asallo Ramos \& M ontenegro Cossio (2008) el IGV grava el consumo como manifestación de riqueza, a diferencia de otros impuestos que gravan la renta o el patrimonio (tal como lo hace el Impuesto a la Renta y el mpuesto $V$ ehicular, respectivamente). Es por ello que estamos ante un impuesto indirecto al gravar una manifestación mediata de riqueza, y agrega que el consumo, desde el punto de vista del IGV, no debe entenderse como efectivo, es decir, que se realice un uso del bien o una utilización propia del servicio, sino que opta por entender que basta que se realice una venta, se preste un servicio o se importe un bien para determine siempre como consumo.

En el mismo contexto, Seminario Dapello (1994) agrega que, los impuestos al gasto, gravan las manifestaciones externas del consumo, o sea aquella parte que las personas obtienen para su consumo del total de bienes y servicios que configuran el producto 0 ingreso de la comunidad, dicho de otra forma, el IGV no afecta la parte de los ingresos que queda en ahorro, sino que grava aquella parte del ingreso que cada quien destina para cansumo.

Por otro lado, bajo la perspectiva de la neutralidad, los impuestos al consumo son considerados regresivos pues, gravando por igual una misma venta 0 servicio, mpactarán más a quienes tienen menos renta que a aquellos que tienen renta mayor, con todo, y dada su importancia en la recaudación de los países, el estándar actual de la técnica prefiere la imposición al consumo de tipo plurifásica no acumulativa (Galindo Villamizar, 2007).

\section{Estructura plurifásica no acumulativa}

La estructura plurifásica no acumulativa es un tipo de impuesto al gasto que posee dos características preponderantes, la de afectar netamente el valor agregado del bien (considerado el mayor valor) discriminando los procesos previos a su circulación económica y ser de uso como un crédito del IGV, pagado por adelantado. En las palabras de Plazas Vega (1998) esta modalidad de la tributación sobre las ventas, el impuesto gravaría ya no la totalidad del precio o el impuesto gravaría ya no la totalidad del precio o el
precio global en todas las "entregas" del bien, como ocurre con el impuesto "plurifase sobre el valor pleno", sino únicamente el "valor agregado" o "valor añadido" en cada uno de los estadios del proceso de fabricación y distribución al por mayor y al por menor del producto. EI gravamen recae en cada caso sobre el mayor valor del bien, agregando Thomas Sick (1981) asume que esta estructura aplica a los bienes y servicios, un impuesto que es exactamente proporcional al precio de los bienes y servicios, independientemente del número de transacciones realizadas en el proceso de producción y distribución precedente a la imposición.

Se infiere que cuando el bien llega al consumidor final, el valor total del bien 0 servicio ha sido proporcionalmente gravado, de acuerdo al valor agregado en cada etapa de su circulación económica. Se entiende, entonces, que esta estructura plurifásica no considera las etapas previamente realizadas para la obtención del bien o servicio final.

A dicionalmente, mediante esta estructura se evita el efecto cascada que se presenta en el sistema acumulativo, dado que en este caso se aplica el impuesto sobre una base que no contiene el impuesto, es decir, no se aplica impuesto sobre impuesto. Esta es la estructura que adopta el IGV que es un estricto impuesto al valor agregado, ya que el objeto de la imposición no es el valor total del consumo, sino el mayor valor o valor agregado que el producto va adquiriendo en cada etapa de la cadena de comercialización (Basallo Ramos \& M ontenegro Cossio, 2008).

Finalmente -haciendo hincapié a la segunda característica- al gravarse a todos los agentes económicos se disminuye la posibilidad de evasión o elusión fiscal en la 
cadena de producción comercialización y, además, el impuesto pagado en una etapa constituye para el adquiriente un crédito contra el impuesto a su cargo, cuando en la siguiente etapa efectúe la reventa, no pasando a integrar parte del costo del bien o servicio y evitando así distorsiones en la formación de precios (Galindo Villamizar, 2007).

\section{O peraciones gravadas}

as operaciones gravadas son un conglomerado de actividades, donde prima el intercambio oneroso de bienes y servicios. En las palabras de Basallo Ramos \& Montenegro Cossio (2008) el IGV peruano grava no solo las operaciones de venta de bienes muebles realizadas en el país, sino también, en algunos casos, la venta de el país, sino también, en algunos casos, la venta de
bienes inmuebles, los servicios e, incluso, los contratos bienes inmuebles, los servicios e, incluso, los contratos de construcción. Según el Artículo 2 del Reglamento de la Ley del Impuesto General a las Ventas (1996) las impuesto son las siguientes:

- La venta en el país de bienes muebles, ubicados en el territorio nacional, que se realice en cualquiera de las etapas del etapas del ciclo de producción y distribución, sean estos nuevos o usados, independientemente del lugar en que se celebre el contrato, o del lugar en que se realice el pago.

Los servicios prestados o utilizados en el país, independientemente del lugar en que se pague 0 se perciba la contraprestación, y del lugar donde se celebre el contrato.

- Los contratos de construcción que se ejecuten en el territorio nacional, cualquiera sea su denominación sujeto que lo realice, lugar de celebración del contrato o de percepción de los ingresos.

La primera venta de inmuebles ubicados en el erritorio nacional que realicen los constructores de los mismos.

La primera venta de inmuebles ubicados en el territorio nacional que realicen los constructores de los mismos.

- La importación de bienes.

\section{Retiro de bienes}

\section{Definición}

Iretiro de bienes puede definirse desde dos puntos de vista: como autoconsumo y como transferencia gratuita, eniendo la característica de estar afecta al IGV por afectar al crédito fiscal de cada entidad. Sustentando la primera idea, V argas (1994) dice que el retiro de bienes que efectúe el propietario, socio o titular de la empresa a la empresa misma, incluyendo los que efectúen como descuento o bonificación, se considera venta afecta al IGV; complementariamente la Comisión de la comunidad andina (2004) señala que, con motivo del retiro de bienes por parte del sujeto pasivo del Impuesto del Valor Agregado (IVA), para un fin distinto a la actividad gravada, se generará el impuesto sobre una base gravable constituida por el valor comercial del bien; por tanto, el retiro de bienes no utilizables o no susceptibles de comercialización por cualquier causa justificada según la legislación interna de cada pais, no estará gravado.

Entonces, por lo mencionado se está frente a una modalidad de operaciones afectas al IGV que busca la regulación del uso del crédito fiscal, ya que no existe un sacrificio patrimonial al realizar un retiro de bienes. A dicionalmente, Villanueva (2009) menciona que con la sujeción de los retiros de bienes se pretende igualar las condiciones entre consumidores finales. Ello ocurre cuando el sujeto del impuesto consume bienes fuera de las actividades empresariales, esto es, cuando realiza autoconsumos no necesarios para realizar las actividades gravadas del contribu pavadas del contribuyente. En estos casos, la premisa para gravar el autoconsumo de bienes es que el sujeto del impuesto ha computado previamente el IVA de compras de los bienes autoconsumidos como crédito fiscal. De manera que la sujeción del autoconsumo pretende igualar las condiciones impositivas entre el consumidor final común y el consumidor final empresa. Ello hace que este último también soporte la carga económica del IVA; adicionalmente B ravo y Villanueva (2009) sostienen que el retiro de bienes como supuesto asimilado a la venta de bienes muebles comprende, por un lado, el consumo de bienes por el titur, socio o empresa misma con destio bienes por en titurino diverso al giro comercial de la empresa y, por otro lado, la transferencia de propiedad de bienes, a titulo gratuito con destino a una actividad no imponible, evitando incremento indebido de la deducción del crédito fiscal.

\section{Actos impropios}

Los actos no lícitos en tributación se conocen como contrarios a los fines de la empresa que, en la mayoría de los casos, son la producción y/o venta de bienes y servicios, así como actos pasivos por parte de los deudores tributarios. Según Ruiz de Castillo (2009) a veces sucede que - con posterioridad a la compra inicialel bien comprado es empleado en una operación no gravada o se transfiere a terceros, debido a un acto de liberalidad: de tal modo que no se está cumpliendo con el objetivo social de la empresa. A quí se advierte un desvío en el destino normal del bien mueble. La mercadería no va a ir a parar a las manos de los clientes; sino de otros sujetos: accionistas, trabajadores de la empresa, etc. De esta manera, no se cumple el objetivo social de la empresa. Por otro lado, García (2010) menciona que los actos impropios son abstenciones de coincidencia y de transferencia económica, y propias, que vienen a ser expresiones inactivas del deudor, después de ocurrido el hecho generador de la respectiva obligación, sea intencionalmente 0 no. Adicionalmente, Alverenga, Pineda \& Raymundo (2010) agrega que el acto impropio estructura sobre la base de la no realización de una acción que se estaba obligado a realizar para evitar un resultado prohibido y que es equivalente a haber realizado activamente dicho resultado.

\section{Tiposderetiro de biene}

El retiro de bienes puede ser visto desde tres ámbitos. De acuerdo al R eglamento de la Ley del Impuesto General a las Ventas (1996) el retiro es considerado como una venta de bien mueble, es decir una operación gravada.

Se entiende por retiro:

- El retiro de bienes muebles que efectúe el propietario, socio o titular de la empresa, o la empresa misma para transferir a terceros:

- El autoconsumo, y

Casos especiales, tales como la extinción de la propiedad por destrucción del bien (merma) o la imposibilidad de su consumo (desmedro).

De manera similar, B ravo \& Villanueva (1998) agrega que el retiro de bienes alude a tres operaciones distintas:

La transferencia de propiedad a título gratuito, entendiéndose como tal a todo acto por el cual se transfiere la propiedad del bien mueble, sin que exista contraprestación recíproca a cambio.

El autoconsumo de bienes efectuado por el socio, titular o la empresa misma, salvo que sea necesario para la realización de operaciones dentro del giro de negocios. En este caso, el autoconsumo recae sobre bienes adquiridos de terceros y no producidos por la propia empresa.

- La autoproducción de bienes que en rigor alude al autoconsumo efectuado por el socio, titular o empresa misma, respecto a los bienes de propia producción.

Según Galindo Villamizar (2007) el retiro de bienes considerado como tal a:
- Todo acto por el que se transfiere la propiedad de bienes a título gratuito, tales como obsequios, muestras comerciales y bonificaciones entre otros.

- La apropiación de bienes de la empresa que realice el propietario, socio o titular de la misma.

- El consumo que realice la empresa de los bienes de su producción o del giro de su negocio, salvo que sea necesario para la realización de las operaciones gravadas.

- La entrega de los bienes a los trabajadores de la empresa, cuando sean de su libre disposición y no sean necesarios para la prestación de sus servicios.

- La entrega de bienes pactada, por convenios colectivos, que no se consideren condición de trabajo y que, a su vez, no sean indispensables para la prestación de servicios.

\section{Autoconsumo}

\section{Definición}

El autoconsumo de bienes puede definirse como la apropiación de los bienes de la empresa que realice el propietario o socio, como si se tratase de un consumidor final y con la característica de no existir un intercambio oneroso. Según Ruiz de Velasco Punin (2012) existe autoconsumo cuando una empresa emplea bienes 0 autoconsumo cuando una empresa emplea bienes 0
servicios producidos por ella en su proceso productivo y servicios producidos por ella en su proceso productivo y
cuando el empresario utiliza bienes 0 servicios producidos en su empresa para su uso o consumo privado 0 para disponer gratuitamente de ellos en favor de terceros, adicionalmente Bravo \& Villanueva (1998) mencionan que el autoconsumo de bienes implica que la empresa se comporta como un consumidor final más, es decir, los consumos que realice no los efectúa dentro del ciclo de producción y comercialización, sino en la posición de consumidor final.

En otras palabra, es la utilización o trasmisión gratuita de bienes 0 servicios de una actividad empresarial o profesional, en beneficio privado del sujeto pasivo o de terceras personas (Fernández de Soto Blas, 2004). A gregando una característica esencial a estas definiciones, A bella Poblet (2006) expresa que se considera como autoconsumo de bienes la transferencia efectuada, por el sujeto pasivo, de su patrimonio empresarial o profesional, a su patrimonio particular.

En este supuesto, al igual que en el de que medie transferencia al consumo particular del titular empresarial, no existe contraprestación por el destino que se da a los 
bienes, así como por la ausencia de dos partes intervinientes en la operación.

El autoconsumo de bienes puede ser realizable bajo dos ópticas: como autoconsumo interno y externo. Se asimilan a las entregas de bienes los autoconsumos de bienes que admiten las siguientes modalidades:

Autoconsumo externo

Este tipo de autoconsumo de clasifica como:

- Transferencia de bienes desde el patrimonio empre sarial o profesional, sin contraprestación alguna, para entregarlos gratuitamente a un tercero.

- Se transmiten bienes desde el patrimonio empresarial o profesional al patrimonio privado o consumo particular del sujeto pasivo, sin que medie contraprestación.

Autoconsumo interno

- Cuando el bien, sin abandonar el patrimonio empresarial o profesional, se afecta a otro sector diferenciado de la actividad empresarial o profesional que otorga un derecho de deducción de menor que otorga un derecho de deducción de menor cuantía que el correspon

- Cuando se afecta a la empresa, como bien de inversión, un bien construido por la propia empresa, evitándose así el gravamen que hubiera soportado de haberse adquirido a terceros. (Centro de Estudios Financieros, 2012)

Según Ruiz de V elasco Punin (2012), tradicionalmente la octrina ha distinguido entre operaciones de autoco sumo exteno y opericiones de autoconsuno inteconsumo externo y operaciones de autoconsumo interno. Se tata de una division de carácter meramente doctrinal, puesto que la LIVA en ningún momento emplea tales expresiones para calificar a las operaciones de autoconsumo, de la misma manera que tampoco lo hace la normativa comunitaria.

El criterio de distinción generalmente admitido se encuentra en el hecho de que la operación transcienda o no del ámbito de la actividad económica, es decir, depende de que la utilización, afectación o destino de los bienes y servicios autoconsumidos tenga lugar en bienes y servicios autoconsumidos tenga lugar en el paring para finalidades ajenas a la propia empresa.

De esta forma, el autoconsumo es externo cuando transciende al exterior de la empresa e implica un consumo 0 un uso gratuito de bienes y servicios de la por parte del propio empresario - pero al margen de su actividad económica, es decir, en su condición de particular-, 0 bien por terceros. En cambio, el autoconsumo interno no transciende de la actividad económica, sino que consiste en una reutilización del bien o servicio de la empresa dentro del propio proceso productivo

\section{Afectación al IGV}

Dado que el autoconsumo no es una operación propia del IGV, la administración tributaria afecta estas operaciones con el impuesto, ya que de lo contrario se ocasionarían con el impuesto, ya que de lo contrario se ocasionarian
distorsiones en el uso del crédito fiscal por las distorsiones en el uso

En las palabras de Gribaldi Pajuelo (2010), en el IGV, aparece el vendedor como contribuyente cuando efectúa la venta de bienes y servicios, sin embargo, la capacidad contributiva, que pretende afectar económicamente este impuesto, es el consumo final de bienes servicios.

Si se inafectase con el IGV al retiro de bienes, se propiciaría que las empresas transfieran gratuitamente bienes a sus socios o trabajadores, lo cual traería como consecuencia un tratamiento tributario inequitativo entre aquellos sujetos que compran bienes en el mercado y aquellos que los reciben gratuitamente de las empresas a las que pertenecen, con la pérdida de la recaudación que ello genera.

Igualmente, cuando la empresa destina los bienes de su producción fuera de sus fines empresariales, se está comportando como un consumidor final (y no como un empresario) por lo que resultaŕa discrimino como un este consumo no se vea ascanzado con el IGV.

Reforzando tal posición, Ruiz de Castilla (2009) asume que la empresa puede realizar el consumo de los bienes de su propia producción, siempre que dicho retiro no sea necesario para que la compañía realice sus operaciones gravadas, dado que se trata de un acto que no es propio (necesario) respecto del objeto social de la empresa.

\section{Conclusión}

Siendo que el retiro de bienes es una extensión de la LIGV, que se considera un supuesto complejo; luego de indagar más acerca de este tema, llegamos a las conclusiones siguientes:
- En primer lugar, el retiro de bienes es parte del IGV que, a su vez, es considerado un impuesto plurifásico no acumulativo, lo cual implica que se aplique el gravamen al valor agregado del bien en cuestión, sin gravamen al valor agregado del bien en cuestion, sin embargo, no se puede hacer uso del crédito que esas
transacciones generen, dado que los retiros se consideran exentos de este beneficio

- Segundo, la clasificación del retiro de bienes se puede dar de dos formas preponderantes: transferencias gratuitas y autoconsumos, siendo la última de estas considerada un acto impropio del

\section{Referencias}

A bella Poblet, E. (2006). Manual del IVA. Madrid: Industria Gráfica MAE S.L.

Alvarenga Orellana, J., Pineda Vásquez, $0 ., \quad \&$ Raymundo Ayala, J. (5 de febrero de 2010). El delito impropio de omisión: Una forma de vulnerar el principio de legalidad en la legislación penal salvadoreña. San Salvador: Universidad de el Salvador.

Andina, C. d. (2004). La decisión 599 - A rmonización de Aspectos sustanciales y procedimientos de los impuestos tipo valor agregado. Reunión del Consejo de Asesor de Ministros de Hacienda O F inanzas (pág. XII). Quito: SICE.

Basallo Ramos, C., \& M ontenegro Cossio, R. M. (2008). $M$ anual operativo del contador $N^{\circ} 6$ aplicación práctica del IG V. Lima: Gaceta J urídica.

Bravo Sheen, D., \& Villanueva Gutierrez, W. (1998). La imposición al consumo en el Perú. Lima: Editorial Tinco S.A.

Centro de Estudios Financieros. (2012). Manual de fiscalidad básica. M adrid: Fiscal Impuestos.

Fernández de Soto Blas, M. L. (2004). Estudio del derecho fical español. Madrid: Editorial Dykinson S.L.

Galindo Villamizar, A. (2007). Régimen tributario peruano. Lima: Legis Perú.

García Navarro, E. (2010). A spectos sustantivos y procesales Enfoque penal al tipo Básico de la defraudación tributaria. Alerta Informativa, 6 . los beneficios aprovechados en la adquisición del bien auto consumido, no estarían formando parte del objetivo principal del ente.

- Finalmente, el autoconsumo de bienes se subdivide a su vez en una parte externa y otra interna, afectando con el impuesto al último de estos -según la ley del IGV - ya que esta no es una operación propia de dicho impuesto.

Gribaldi Pajuelo, G. (2010). Aproximaciones al retiro de bienes gravado con el IGV. Lima: Dirección de Informática A cadémica PUCP.

Plazas Vega, M. (1998). El impuesto sobre el valor agregado. Santa Fe de Bogotá: Temis S.A.

Ruiz de Castilla Ponce de León, F. (15 de agosto de 2010). El retiro de bienes en el IGV (Parte I). Actualidad Empresarial, I(212), 1.

Ruiz de Velasco Punin, C. (2012). La tributación del autoconsumo en el impuesto sobre el valor añadido. M arcial Pons, $16-17$.

Seminario Dapello, A. (1994). Temas financieros sobre impuestos. Lima: Cultural Cuzco.

Thomas Sick, F. (1981). El impuesto sobre el valor agregado en el contexto tributario guatematelco Tesis. Guatemala: Universidad Francisco Marroquín.

Tributaria, S. N. (31 de 12 de 1996). Reglamento de la Ley del Impuesto General a las V entas e Impuesto Selectivo al Consumo. Reglamento. Lima, Lima, Lima: Legis Perú.

Villanueva Gutierrez, W. (2009). Estudio del impuesto al valor agregado en el Perú. Lima: Tax Editor. 